\title{
An Investigation on the Influence of Organizational Culture and Justice towards
}

\section{Employees' Performance}

\author{
* Dr. Irfan Ullah Khan \\ ** Muhammad Saqib Khan \\ *** Dr. Rooh Ul Amin
}

\begin{abstract}
Performance management is a phenomenon of greater importance for all organizations including the institutions of higher education (HEIs) to attain their desired ranking in competitive situations. The performance is considered as building blocks for organizations to survive and to more towards development. Numerous factors are responsible to influence the performance in institutions among which the organizational culture and justice are phenomenal. This study is an effort to observe the influence of both variables (culture \& justice) in influencing the performance of employees in HEIs. The data was collected from teaching faulty (population) over questionnaire hailing from higher institutions of the southern region of Khyber Pakhtunkhwa, Pakistan and was examined by applying diverse statistical procedure about relationships among the research variables which were extracted from the theoretical framework. The study offers valuable information about the relationship among research variables under study by offering some commendations to the policymakers and future researchers.
\end{abstract}

Keywords: Organizational Justice, Organizational Culture, Employees Performance, HEIs Introduction

In developed as well as developing countries, the higher institutions are considered as the backbone for developing the civilized societies. During past decades, the higher institutions have shown substantial development and this role is more exposed in the context of Pakistan about the public and private sector institutions (Niazi, \& Mace, 2006). Through higher education commission, the government of Pakistan, spending more funds on the research and development to develop the educational excellence and standards of institutions at par to the international standards (Haider, \& Sultan, 2008). However, some quality measures about financial crises, administrative deadlocks, and improvement in enrollment are still direly needed to cater to the situation and to meet international standards (Osman, Munever, Dogan, \& Nermin, 2010). These standards can only be achieved over a healthy performance management system supported by sustainable culture and justifiable justice. This may help in reshaping the employees' behavior towards long-term objectives attainment of the higher institutions in "developing countries" like Pakistan.

The higher institutions might be able to obtain the desired standards only when there exists an effective performance management system in the institutions. The performance of these institutions is contingent upon the performance of their employees as both are reinforcing each other (Ehtesham, \& Shakil, 2011). The employees' efforts at institutions serve as the framework in describing the institutional status as well as helps in gauging the institutional competitive lead. In this connection, the performance has been considered as a critical issue and each institution desires the respectable performance from its employees (Koopmans, Bernaards, Hildebrandt, Buuren, \& Beek, 2013). In this regard, the magnitude and quality of performances depend upon the contextual parameters and the managerial effectiveness. However, "there are certain other factors which are responsible" in increasing or decreasing the performances of the employees in higher institutions (Saima, \& Akhtar,

* Department of Public Administration, Gomal University, Dera Ismail Khan, KP, Pakistan

** Department of Business Administration, Gomal University, Dera Ismail Khan, KP, Pakistan

*** Department of English, Gomal University, Dera Ismail Khan, KP, Pakistan 
2015). Among these factors, organizational culture and justice are measured as the most effective issues which are responsible for influencing the performance.

The organizational culture has been measured as the philosophy that boosts the norms and values of the institutions in desirable manners. The supportive and sustainable culture helps in increasing employee's performance optimistically that promotes the internationalization of higher education (Zakaria, Fida, \& Janjua, 2016). The strong culture has been recognized as the constituent for constant development and considered a strong predictor for decent performances that leads to sustainable viable excellence towards the credibility of higher institutions (Ahmed, \& Mostafa, 2017). Similarly, just culture helps build the just decisions leading to organizational justice. The fairness perception of employees at the workplace not only helps in shaping the employees' attitude positively but also helps in growing their performances (Ismail, Iqbal, \& Adeel, 2018). The justice is the perception of employees about the fairness in the procedures, equality is distributions and the likeness in interactions leading to higher morale and undaunted commitment on the part of employees (Pracha, Malik, Azeem, \& Yasmin, 2020).

Organizational justice and culture have been considered as the leading issues that are directly related to the institutional credibility and success. These issues (justice \& culture) have been widely researched in different contexts. Keeping in view the trend, this study also examined the role of organizational justice and culture in determining employee's performance. Therefore, the issue addressed in the current study is related to the analysis of employees' performance through "organizational justice and culture" in the context of HEIs of Khyber Pakhtunkhwa, Pakistan. The viable cultures and just decisions have been considered as strong predictors for employees' performance which has been aimed to validate in this study by conducting the study in a native environment.

\section{Objectives of Study}

$\checkmark \quad$ To examine organizational culture, justice, and employees' performance in the context of higher institutions by revisiting the theoretical support and confirmed it through empirical investigations (Main objective).

$\checkmark \quad$ To examine the association between organizational culture, organizational justice, and employees' performance in the context of HEIs of Khyber Pakhtunkhwa, Pakistan (correlation).

$\checkmark$ To examine the impact/influence of "organizational culture" and justice on employee performance in the context of higher institutions of the Khyber Pakhtunkhwa, Pakistan (regression).

\section{Literature Review}

The current study is an effort to explore the connection amid organizational culture, justice, and employees' performance in the higher education context. The variables have been selected carefully from the existing research and converted into a theoretical framework from where the assumptions have been developed about the possible relationships among the research variables. These variables have been already researched in different contexts with different outcomes (Erdogan, Liden, \& Kraimer, 2006). The organizational culture is widely predicted as a strong forecaster of employees' performance which has been confirmed over empirical studies by confirming the significant associations and "impact of organizational culture" on employees' performance "(Gregory, Harris, Armenakis, \& Shook, 2009)". Likewise, justice has also been widely researched in a higher educational context with significant results towards different organizational outcome variables including the employees' performance (Arman, Latif, \& Ali, 2014). Thus, the culture and justice help reshape the citizen-ship behavior as well as the performances of the employees as per the desired standards and norms and values of the institutions (Ismail, Iqbal, \& Adeel, 2018).

\section{Organizational Culture}

The culture has been described by researchers over diverse dimensions by considering it as an amalgamation of the values and beliefs, expectations, and the behavioral understanding towards institutional objectives "(Bititci, Mendibil, Nudurupati, Garengo, \& Turner, 2006)". The culture is the framework of basic values that the individual perceives to manage the problems related to the external adaptation and internal integration to prioritize the institutional objectives (Ehtesham, \& Shakil, 2011). Besides, in the existing research, values of organizational culture towards the performance 
(organizational \& employees) mark the dimensions to determine and resolve undeveloped concerns (Pavel, \& Adina, 2014). These concerns mainly comprise the survival of the internal processes, adaptation, and integration that enables the institutions to survive and develop their priorities in the modern competitive environment (Thokozani, \& Maseko, 2017). Thus, the strong culture of higher institutions is likely to have a strong influence on employees and institutional performance that leads to a higher level of productivity and outcomes concerning the desired standards (Markos, Sang, \& Muthanna, 2019).

\section{Organizational Justice}

The organizational justice, in higher educational context, has been measured as the critical success factor for the institutions to survive and develop in the contemporary competitive environments (Aryee, Che, \& Budhwar, 2004). The just environment of higher institutions that are respected, accepted, and valued for all the stakeholders is expected to have a prolonged impact on institutional credibility and success (Ambrose, Hess, \& Ganesan, 2007). The fair environment is requisite for the higher institutions wherein the employees can express their views without restrictions and where their ideas are respected based upon institutional development (Hassan, \& Hashim, 2011). The individuals' perceptions about fairness in the processes, practices, and measures are presumed to have significant emotional influence on work outcomes (attitude \& behavior) of the employees (Hassan, \& Hassan, 2015). Likewise, the individuals are expected to respond to the institutional procedure more positively when values are favorable and when the institutions are fair in interacting through individualized considerations (Pracha, Malik, Azeem, \& Yasmin, 2020).

\section{Employees Performance}

Excellence in performance is believed as a significant predictor for institutional success as the credibility of higher institutions is pivot around the respectable level of performances on the part of their employees (Armstrong, \& Baron, 2005). It is an accredited fact employees' effectiveness and efficiency resides in a rational position in performance management system wherein the feelings behavior of the employees defines the motivation and values towards the institutions in different situations (Bowles, \& Cooper, 2009). Similarly, innovativeness and responsiveness are also considered as important attributes for performance in diverse situations as these are measured as overwhelming attributes in measuring the overall performance (Mohamed, \& Abukar, 2013). Creativity and innovation are important for nurturing the innovative work behavior leading to higher performances of the employees in different situations in the institutions (Irfan, Nawaz, Qamar, \& Zakeer, 2016). This may help in eliminating the undesirable eventualities likewise, employees' burnout, stress, anxieties, and absenteeism at the workplace.

\section{Organizational Culture, Justice and Performance}

The existing research studies offered considerable literature about associations between organizational justice, culture, and employees' performance in different contexts including the higher education institutions (Erdogan, Liden, \& Kraimer, 2006). The supportive culture is vital for enhancing the employees' morale and perception about the applications of the institutional norms and values in effective manners to attain the desired objectives (Hakan, 2011). The just culture is inspirational in influencing employees' behavior positively and work with the domain of institutional norms and values by showing their utmost efforts and potential in chasing the institutional goals (Saima, \& Akhtar, 2015). Similarly, justice is also a significant predictor towards respectable performances on the part of employees which may help to chase institutional objectives more efficiently and effectively in institutions (Benson, \& Martin, 2017). Consequently, organizational justice and culture are influencing the employees' behaviors positively as well as negatively based upon the application of these concepts variables in different contexts and situations including HEIs of the developing countries like Pakistan (Pracha et al., 2020).

\section{Theoretical Framework}

The theoretical framework helps in confirming and understanding the concepts used in the study along with understanding the relationships among research variables that have been presented through arrows that show the direction. 
Figure 1 Theoretical Framework

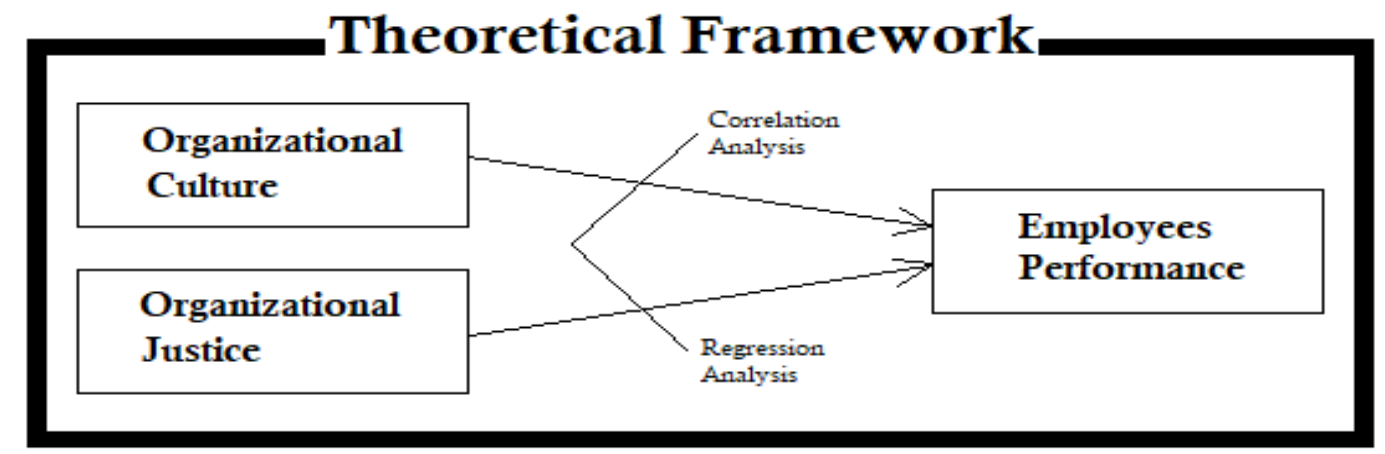

Research Hypotheses

$\mathrm{H}_{1}$ : The independent variables are positively correlated (associated) with the dependent variable $\mathrm{H}_{2}$ : The independent variables have a positive and significant impact on the dependent variable

\section{Research Design}

The methods and procedures for conducting the research have been always mentioned in the research design of the study. It explains the complete process of research from its inception to conclusion. It helps in clarifying the procedures concerning data collection and analysis. It further helps in finding the answers to the research hypotheses. In this regard, the exploratory research design (descriptive \& inferential) has been used to examine relationships among research variables through different procedures.

\section{Research Approach}

Every philosophical approach has its requirements based upon the nature of the research study. The current study is an attempt to examine the existing realities in the native environment by using different statistical procedures that are matched with assumptions of the positivism approach consequently, positivism is a philosophy of research adopted in this research. Similarly, the "survey approach has been used" to conduct the study.

\section{Population and Sample}

The population is an important part of research that comprises the objects of the research study. Thus, researchers collect data from samples and try to generalize it to the population. The population comprises the teaching faculty of higher educational institutions hailing from the southern region of Khyber Pakhtunkhwa, Pakistan. The data from a Ph.D. dissertation has been used in this study. The total population comprises 1740 teaching faculty wherein a sample of 356 has been selected by using the statistical formula (Yamani, 1967). The random sampling technique was used. So, 356 questionnaires were distributed among which 322 were recollected with a response rate of $90 \%$.

\section{Data Collection and Analysis}

The secondary data was mustered over different research articles available on the different websites of research journals while "primary data has been collected over questionnaire". The adapted questionnaire has been used from the existing research studies. The data was then "analyzed by using different statistical tools to find out answers to research questions and to reach the conclusion".

\section{Research Context and Measurement}

The present research has been conducted in the context of HEIs as these institutions are playing an important role in teaching and learning thus providing substantial socio-academic and socio-economic support in the developmental process. The questionnaires were adapted from the existing studies likewise the organizational culture (Denison, 1997), organizational justice (Greenberg, 1990), and employees' performance (Uphoff \& Muharir, 1994). Measurement of variables was done through the validity and reliability examinations.

\section{Ethical Considerations}

The ethical standards have been ensured in the study. During primary research, the most important basics are the participation (voluntarily), confidentially and privacy factor of the participants. Similarly, another dynamic feature of the research is to ensure the privacy of the respondents. The confidentiality is vital to keep the information about respondents as confidential. 


\section{Reliability Examination}

The reliability examination was done through Cronbach Alpha which provides sufficient data in deciding the reliability of the measure. Likewise, the Cronbach Alpha for organizational culture (.830) organizational justice (.836) and employees' performance (.950). The results show that the measure has good reliability in terms of internal consistency.

Table 1 Reliability Statistics

\begin{tabular}{clcc}
\hline S.No. & \multicolumn{1}{c}{ Variables } & No. of Items & Cronbach's Alpha \\
\hline 1 & Organizational Culture & 12 & .830 \\
2 & Organizational Justice & 12 & .836 \\
3 & Employees Performance & 16 & .950 \\
4 & Questionnaire & 40 & .919 \\
\hline
\end{tabular}

\section{Results and Discussions}

Answering the research questions is simply the process of data analysis. The descriptive, as well as the inferential analysis, have been used by presenting the descriptions of the research variables as well as the "relationships among the research variables". Similarly, the outcomes have been discussed and matched with the prevailing studies in terms of commonalities and differences to make clear the position of this study in the existing database of knowledge concerning the issues under considerations.

\section{Descriptive Analysis}

The "descriptive analysis provides" the information about describing the research variables in terms of the mean, standard deviation, minimum and maximum response. 7-point "Likert scale was used" to collect the responses from the responses which have been mentioned in the table given below:

Table 2 Descriptive Statistics

\begin{tabular}{lccccc}
\hline & N & Minimum & Maximum & Mean & Std. Deviation \\
\hline Organizational Culture & 322 & 1.76 & 6.69 & 4.4119 & 1.00900 \\
Organizational Justice & 322 & 2.03 & 6.89 & 4.0142 & .98547 \\
Employees Performance & 322 & 1.80 & 7.00 & 4.3707 & 1.22782 \\
Valid N (list-wise) & 322 & & & & \\
\hline
\end{tabular}

\section{Inferential Analysis}

The inferential analysis helps in offering information about "relationships among" the research variables. The correlation has been "used to examine the strength" and direction of relationships concerning the association while the regression has been used to observe the cause-\&-effect "relationship among the research variables".

$\mathrm{H}_{1}$ : The independent variables are positively correlated (associated) with the dependent variable

Table 3 Correlation Analysis

\begin{tabular}{llcc}
\hline & & Culture & Justice \\
\hline Organizational Culture & Pearson Correlation & 1 & $.728^{* *}$ \\
& Sig. (2-tailed) & & .000 \\
& $\mathrm{~N}$ & 322 & 322 \\
Organizational Justice & Pearson Correlation & $.728^{* * *}$ & 1 \\
& Sig. (2-tailed) & .000 & 322 \\
& $\mathrm{~N}$ & 322 & $.815^{* *}$ \\
Employees Performance & Pearson Correlation & $.849^{* *}$ & .000 \\
& Sig. (2-tailed) & .000 & 322 \\
\hline
\end{tabular}

**. Correlation is significant at the 0.01 level (2-tailed).

The hypothesis about association provides significant information in deciding relationships in terms of association. The results show that independent variables (organizational culture \& organizational justice) are significantly and highly linked with employees' performance (dependent variable). Organizational culture is "positively and significantly associated with the employees' performance" (Pearson $=.849 \&$ P-value $=.000)$, while the organizational justice is positively and significantly correlated with employee performance (Pearson $=.815 \&$ P-value $=.000)$. The results of the study have been supported through the existing research studies wherein the same results have been witnessed (Aryee, Chen \& Budhwar, 2004; Balthazard, Cooke \& Potter, 2006; Devonish, \& Greenidge, 2010; Ali \& Musah, 2012; Arman, Latif \& Ali, 2014; Boyce, Nieminen, Gillespie, Ryan \& Denison, 2015; Ismail, Iqbal \& Adeel, 2018; Markos, Sang \& Muthanna, 2019). 
$\mathrm{H}_{2}$ : The independent variables have a positive and significant impact on the dependent variable Table 4 Regression Analysis (Model Summary)

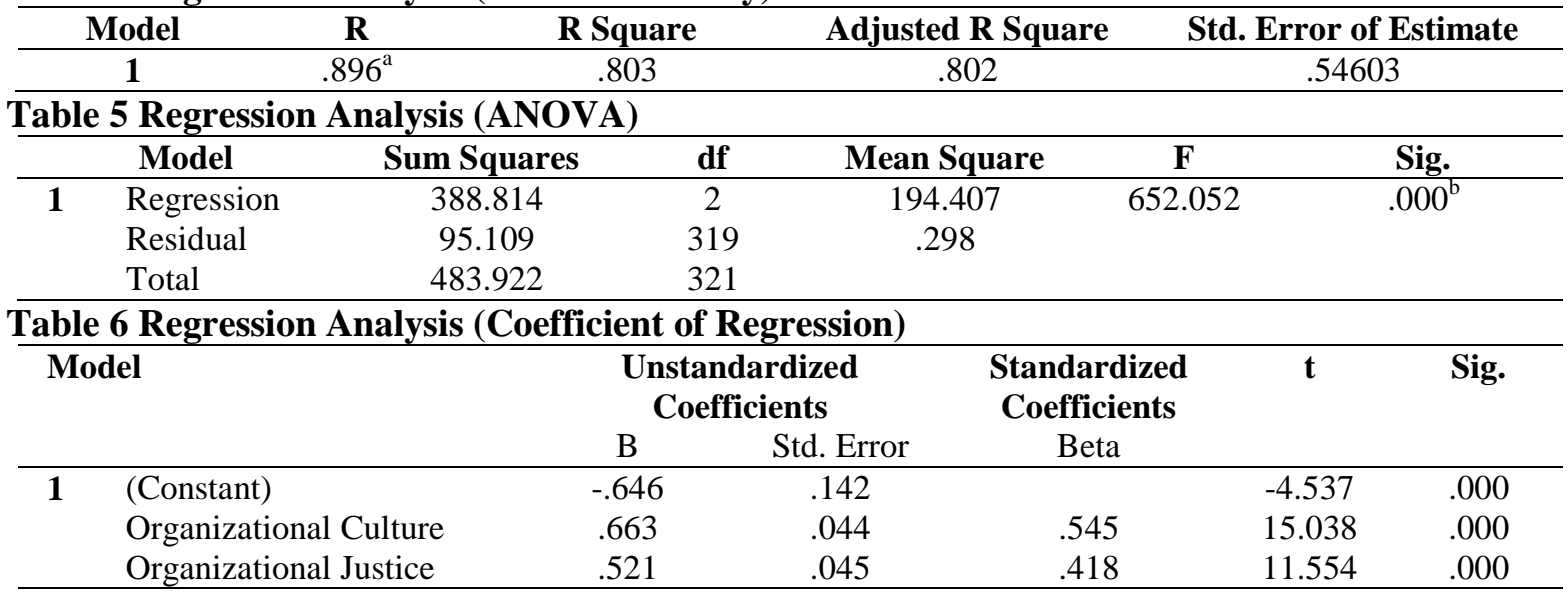

a. Independent Variables: Organizational Culture \& Organizational Justice

b. Dependent Variable: Employees Performance

The hypothesis about the cause-\&-effect relationship was examined by using the regression procedure. The results show that there is an $80 \%$ deviation in criterion variable (employees' performance) is because of independent variables (organizational culture \& organizational justice). The ANOVA table also show significance while coefficients of regression confirmed the "impact of organizational culture on employees' performance" (coefficient $=.663 \&$ P-values $=.000$ ) and organizational justice on employees' performance (coefficient $=.521 \&$ P-values $=.000$ ). The results of regression provide significant information in deciding the cause-\&-effect relationships. The results of regression have been validated through results of existing research studies (Gendy \& Banna, 2007; Ehtesham \& Shakil, 2011; Mohamed \& Abukar, 2013; Menaka \& Chandrika, 2015; Mehmood, Norulkamar \& Ahmad, 2016; Ibrahim, Ali \& Kazeem, 2017; Markos, Sang \& Muthanna, 2019).

Conclusion

The study was aimed to examine the relationships among organizational culture, justice, and employees' performance. The assumptions about the relationships were extracted from the theoretical framework which has been analyzed by using the statistical procedures. The results show that organizational justice and culture are "significantly associated with the employees' performance" while the significant impact has also been evident by applying the regression procedure. Results have been confirmed over results from prevailing research studies as "conducted from time to time in different contexts". The organizational culture helps inspire employees to work within the "norms and values of the organization" in the present case, higher institutions while the organizational justice helps in nurturing the employees' positive and fair perceptions about organizational actions. Both these concepts are vital in determining the employees' attitude and behavior by inspiring them to achieve their assigned responsibilities effectively and efficiently. Some recommendations have emerged from the results of the study for eye-openers to revisit their policies concerning the organizational culture, organizational justice, and employees' performance in the context of higher educational institutions.

\section{Recommendations}

$\checkmark \quad$ The higher institutions are direly needed to "focus more" on organizational culture, justice, and performance to strengthen is competitive advantages and to promote its sustainable development.

$\checkmark \quad$ The institutions are required to promote fair policies concerning the employees in terms of resource distribution, procedures, and interactions so that they might be able to show their wholehearted performance.

The institutions are required to promote the institutional norms and values by encouraging strong culture so that the employees might be able to work within the domain of just cultures in the institutions. 


\section{Implications for Future Research}

$\checkmark \quad$ Future researchers are required to conduct the same study by using the same model in other organizations including private and public to examine the role of organizational culture, justice, and performance in the different work environments.

$\checkmark \quad$ Future scholars are advised to use some mediators in connecting organizational culture, justice, and performance so that some more significant information may be expected about the "relationships among research variables".

$\checkmark \quad$ The current study was focused on a limited number of HEIs in KP, province however, in future studies, some other HEIs may be included to generalize and strengthen the findings on

\section{References} the same phenomenon under considerations.

Ahmed, M., \& Mostafa, S. (2017). High-performance HR practices, positive affect, and employee outcomes. Journal of Managerial Psychology, 32 (2), 163-176.

Ali, H. M., \& Musah, M. B. (2012). Investigation of Malaysian higher education quality culture and workforce performance. Quality Assurance in Education, 20 (3), 289-309.

Ambrose, M. L., Hess, R. L., \& Ganesan, S. (2007). The relationship between justice and attitudes: An examination of justice effects on event and system-related attitudes. Organizational behavior and human decision processes, 103 (1), 21-36.

Arman, H., Latif, L. A., \& Ali, J. (2014). Organizational Justice as a predictor of self-perceived work performance: A perspective from the Malaysian higher educational institution. Mediterranean Journal of Social Sciences, 5 (23), 319-325.

Armstrong, M., \& Baron, A. (2005). Managing Performance: Performance Management in Action. London, Chartered Institute of Personnel and Development.

Aryee, S., Chen, Z. X., \& Budhwar, P. S. (2004). Exchange fairness and employee performance: an examination of the relationship between organizational politics and procedural justice. Organizational Behavior and Human Decision Processes, 94, 1-14.

Balthazard, P., Cooke, A., \& Potter, R. (2006). Dysfunctional culture, dysfunctional organization: Capturing the behavioral norms that form organizational culture and drive performance. Journal of Managerial Psychology, 21 (8), 709-732.

Benson, T. H., \& Martin, L. (2017). The effect of inter-organizational justice perceptions on organizational citizenship behaviors in construction projects. International Journal of Project Management, 35, 95-106.

Bititci, U., Mendibil, K., Nudurupati, S., Garengo, P., \& Turner, T. (2006). Dynamics of performance measurement \& organizational culture. International Journal of Operations \& Production Management, 26 (12), 1325-1350.

Bowles, D., \& Cooper, C. (2009). Employee morale: Driving performance in challenging times. Palgrave Macmillan. New York.

Boyce, A. S., Nieminen, L. R., Gillespie, M. A., Ryan, A., \& Denison, D. (2015). Which comes first, organizational culture or performance? A longitudinal study of causal priority with automobile dealerships. Journal of Organizational Behavior, 36 (3), 339-359.

Denison, D. R. (1997). Denison Organizational Culture Survey. Facilitator Guide. Daniel R. Denison and William S. Neale, Washington.

Devonish, D., \& Greenidge, D. (2010). The effect of organizational justice on contextual performance, counterproductive work behaviors, and task performance: Investigating the moderating role of ability-based emotional intelligence. International Journal of Selection and Assessment, 18, 1, 76-86.

Ehtesham, M., \& Shakil, A. (2011). Impact of organizational culture on performance management practices in Pakistan. Department of Management Sciences, COMSATS Institute of Information Technology, Islamabad, Pakistan.

Erdogan, B., Liden, R., \& Kraimer, M. L. (2006). Justice and leader-member exchange: The moderating role of organizational culture. Academy of Management Journal, 49, 395-406.

Gendy, A., \& Banna, A. (2007). The feel of organizational justice and its relationship with the evaluation of job performance and the awareness of the psychological dimensions of the educational environment. The Future of Arabic Education Journal, 13 (47), 9-130. 
Greenberg, J. (1990). Organizational justice: Yesterday, today and tomorrow. Journal of Management, 16: 399-432.

Gregory, B. T., Harris, S. G., Armenakis, A. A., \& Shook, C. L. (2009). Organizational culture and effectiveness: A study of values, attitudes, and organizational outcomes. Journal of Business Research, 62, 673-679.

Haider, Z., \& Sultan, S. (2008). Challenges in higher education: Special reference to Pakistan and South Asian developing countries. Nonpartisan Educational Review, 4, 1-12.

Hakan, E. (2011). The moderating role of organizational culture in the relationship between organizational justice and organizational citizenship behaviors. Leadership \& Organization Development Journal, 32 (6), 532-554.

Hassan, A., \& Hashim, J. (2011). Role of organizational justice in determining work outcomes of national and expatriate academic staff in Malaysia. International Journal of Commerce and Management, 21 (1), $82-93$.

Hassan, S., \& Hassan, M. U. (2015). Testing the mediating role of perceived organizational support between leadership styles, organizational justice, and employees' behavioral outcomes. Pakistan Journal of Commerce and Social Sciences, 9 (1), 131-158.

Ibrahim, R., Ali, B., \& Kazeem, B. K. (2017). Organizational culture and development: Testing the structural path of factors affecting employees' work performance in an organization. Asia Pacific Management Review, 22, 104-111.

Irfan, U. K., Nawaz, A., Qamar, A. Q., \& Zakeer, A. K. (2016). The Impacts of Job Burnout and Absenteeism on Employees Performance in HEIs. Information and Knowledge Management, $6(1), 1-4$.

Ismail, S., Iqbal, Z., \& Adeel, M. (2018). Impact of Organizational Justice and Organizational Citizenship Behavior on Employees Performance. International Journal of Human Resource Studies, 8 (2), 187-200.

Koopmans, L., Bernaards, C. M., Hildebrandt, V. H., Buuren, S., Beek, A. (2013). Development of an individual work performance questionnaire. International Journal of Productive Performance Management, 62 (1): 6-28.

Markos, T., Sang, G., \& Muthanna, A. (2019). Organizational culture and its influence on the performance of higher education institutions: The case of a state university in Beijing. International Journal of Research Studies in Education, 8 (2), 77-90

Mehmood, N., Norulkamar, U., \& Ahmad, U. (2016). Organizational justice and employee performance: Evidence from Higher Education Sector in Pakistan. Journal Kemanusiaan, 25 (2), 48-56.

Menaka, H. S., \& Chandrika, K. A. (2015). Impact of Organizational Culture on Employee Job Performance in a Large Scale Apparel Company. 2nd International HRM Conference, 2 (1), 65-74.

Mohamed, A., \& Abukar, A. (2013). The impact of organizational culture on employees' performance of Mogadishu universities. Academic Research International, 4 (6), 382-391.

Niazi, H., \& Mace, J. (2006). the contribution of the private sector to higher education in Pakistan with particular reference to efficiency and equity. Bulletin of Education \& Research, 28 (2), $17-42$.

Osman, F., Munever, Y., Dogan, M., \& Nermin, K. (2010). The Organizational Culture at the University. The International Journal of Educational Researchers, 2 (1), 1-13.

Pavel, K., \& Adina, P. (2014). Quality Culture - A Key Issue for Romanian Higher Education. Social and Behavioral Sciences, 116, $3805-3810$.

Pracha, A., Malik, S., Azeem, M., \& Yasmin, R. (2020). Impact of Organizational Justice on Employee Performance: Mediating Role of Emotional Intelligence: An Analysis of Public Sector Organizations of Pakistan. Journal of Managerial Sciences, 11 (03), 215-334.

Saima, M., \& Akhtar, S. (2015). Relationship between organizational culture and organizational effectiveness in public and private sector universities of Pakistan. Science International, 27 (3), 1891-1897.

Thokozani, S., \& Maseko, B. (2017). Strong vs weak organizational culture: Assessing the Impact on Employee Motivation. Arabian Journal of Business and Management Review, 7 (1), 2-5. 
Uphoff, N., \& Moharir, V. (1994). An analytical model of performance for developing indicators of employees' capability. Journal of Public Administration, 17 (3), 372-379.

Yamani, T. (1967). Statistics: An Introductory Analysis, 2nd Edition, And New York: Harper and Row.

Zakaria, M., Janjua, S., \& Fida, B. (2016). Internationalization of Higher Education: Trends and Policies in Pakistan. Bulletin of Education and Research June, 38 (1), 75-88. 